
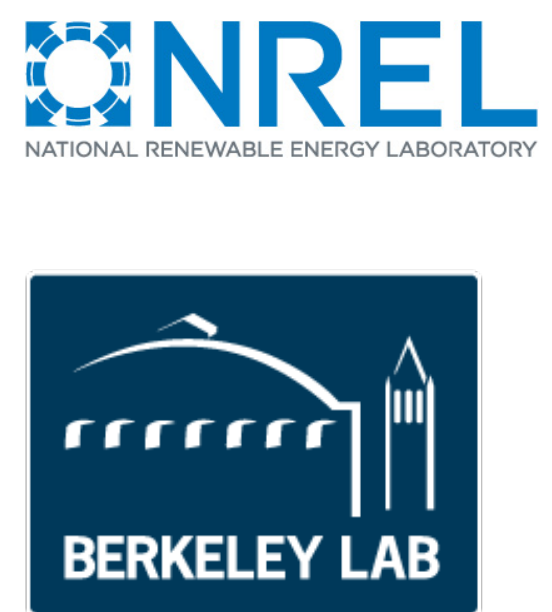

\title{
Aligning PEV Charging Times with Electricity Supply and Demand
}

\author{
Cabell Hodge \\ National Renewable Energy Laboratory
}

Produced under direction of the DOE Office of International Affairs and the Clean Energy Ministerial by the National Renewable Energy Laboratory (NREL) and Lawrence Berkeley National Laboratory under Task No. DSEV.1030.

NREL is a national laboratory of the U.S. Department of Energy Office of Energy Efficiency \& Renewable Energy Operated by the Alliance for Sustainable Energy, LLC

This report is available at no cost from the National Renewable Energy Laboratory (NREL) at www.nrel.gov/publications.

Strategic Partnership Project Report

NREL/TP-5400-68623

June 2017

Contract No. DE-AC36-08GO28308 

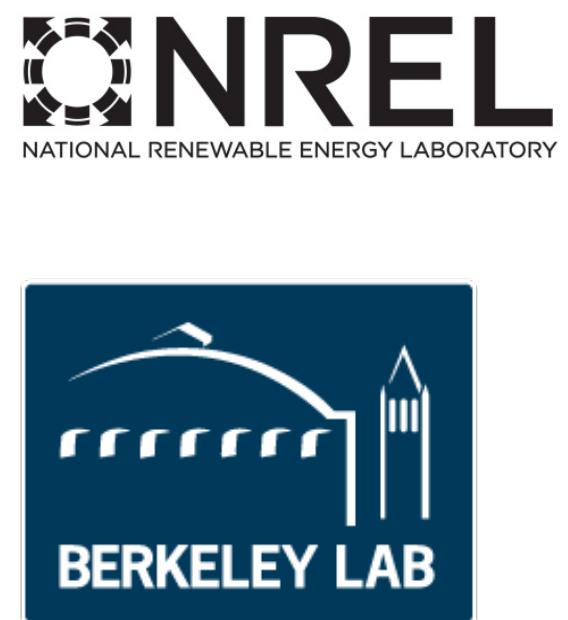

\section{Aligning PEV Charging Times with Electricity Supply and Demand}

\author{
Cabell Hodge \\ National Renewable Energy Laboratory
}

Prepared under Task No. DSEV.1030
NREL is a national laboratory of the U.S. Department of Energy Office of Energy Efficiency \& Renewable Energy Operated by the Alliance for Sustainable Energy, LLC

This report is available at no cost from the National Renewable Energy Laboratory (NREL) at www.nrel.gov/publications.

Strategic Partnership Project Report

NREL/TP-5400-68623

June 2017

Contract No. DE-AC36-08G028308
National Renewable Energy Laboratory 15013 Denver West Parkway

Golden, CO 80401

303-275-3000 • www.nrel.gov 


\section{NOTICE}

This manuscript has been authored by employees of the Alliance for Sustainable Energy, LLC ("Alliance") under Contract No. DE-AC36-08GO28308 with the U.S. Department of Energy (“DOE”).

The tables and figures in this report are limited to use in this report only and are not to be further disseminated or used without the permission of the sources cited.

This report was prepared as an account of work sponsored by an agency of the United States government. Neither the United States government nor any agency thereof, nor any of their employees, makes any warranty, express or implied, or assumes any legal liability or responsibility for the accuracy, completeness, or usefulness of any information, apparatus, product, or process disclosed, or represents that its use would not infringe privately owned rights. Reference herein to any specific commercial product, process, or service by trade name, trademark, manufacturer, or otherwise does not necessarily constitute or imply its endorsement, recommendation, or favoring by the United States government or any agency thereof. The views and opinions of authors expressed herein do not necessarily state or reflect those of the United States government or any agency thereof. 


\section{Acknowledgments}

This work was supported by the U.S. Department of Energy under Contract No. DE-AC3608GO28308 with the National Renewable Energy Laboratory. Funding provided by the U.S. Department of Energy Office of International Affairs. The author would like to thank John Barnett, Anand Gopal, Rudy Kahsar, Andrew Meintz, Margo Melendez, Matteo Muratori, and Darlene Steward for their reviews and input. In addition, the author would like to thank Heidi Blakley for her diligence, responsiveness, and attention to detail while editing this report. 


\section{Executive Summary}

Plug-in electric vehicles (PEVs) are a growing source of electricity consumption that could either exacerbate electricity supply shortages or smooth demand curves. Extensive research has explored how vehicle-grid integration (VGI) can be optimized by controlling PEV charging timing or providing vehicle-to-grid (V2G) services, such as storing energy in vehicle batteries and returning it to the grid at peak times. However, implementation in the real world requires a cost-effective solution that accounts for consumer behavior. To function across different contexts, several types of charging administrators and methods of control are necessary to minimize costs in the VGI context.

Charging control mechanisms can include the PEV interface, an electric vehicle supply equipment (EVSE) network, facility energy management, and price signals. These levels of control are appropriate for different users and each carries unique benefits and drawbacks. This work examines the relative advantages and disadvantages of each control mechanism and how they interrelate.

The technologies only function properly if utilities structure rates to have an influence on charging patterns. At low rates of PEV penetration, simple residential time-of-use (TOU) rates can encourage drivers to use the vehicle interface to set charging start times. At high PEV penetration levels, dynamic rates and automated control will better smooth charging loads. Similarly, simple demand rates at commercial enterprises are sufficient in most markets to discourage charging coincident with peak demand as long as a PEV interface or EVSE network is utilized. However, integration with facility energy management may better align charging times than a stand-alone EVSE network. Furthermore, large scale PEV deployment may require greater integration at the system level, which may involve more complicated pricing mechanisms and automated, aggregate controls. 


\section{Table of Contents}

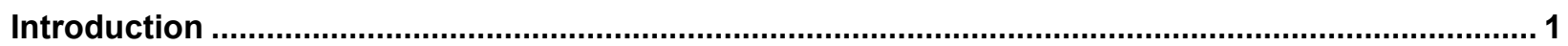

Plug-In Electric Vehicle Interface Control ......................................................................................... 2

Electric Vehicle Supply Equipment Networks ................................................................................ 3

Integrated Facility Energy Management System............................................................................ 4

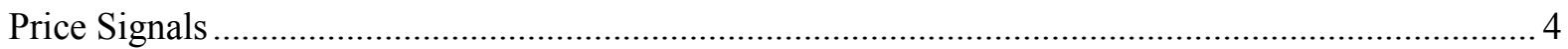

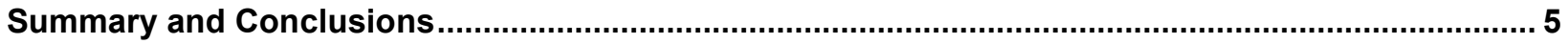

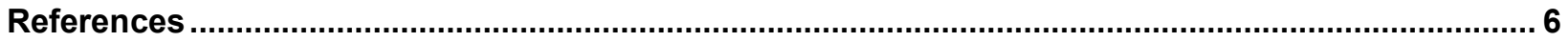

\section{List of Figures}

Figure 1. CAISO lowest March daytime net load—non-renewable generation needs....................... 1

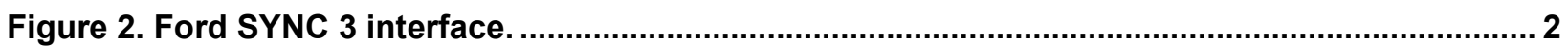

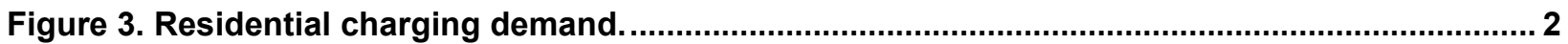

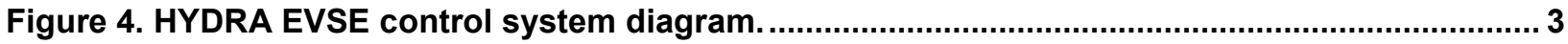

\section{List of Tables}

Table 1. Summary of Charging Control Mechanisms 


\section{Introduction}

Large quantities of solar and wind power often generate electricity at times of low consumer demand, such as mid-morning or the middle of the night. The California Independent System Operator (CAISO) uses the so-called "Duck Curve" to illustrate how large quantities of solar photovoltaic generation interact with consumer demand to create steep ramps upward and downward in generation needs (California ISO 2016). ScottMadden Management Consultants' review of CAISO data shows how low the belly of the Duck Curve actually dipped in 2016 in Figure 1, which is lower than initially predicted in 2013 (Vlahoplus et al. 2016).

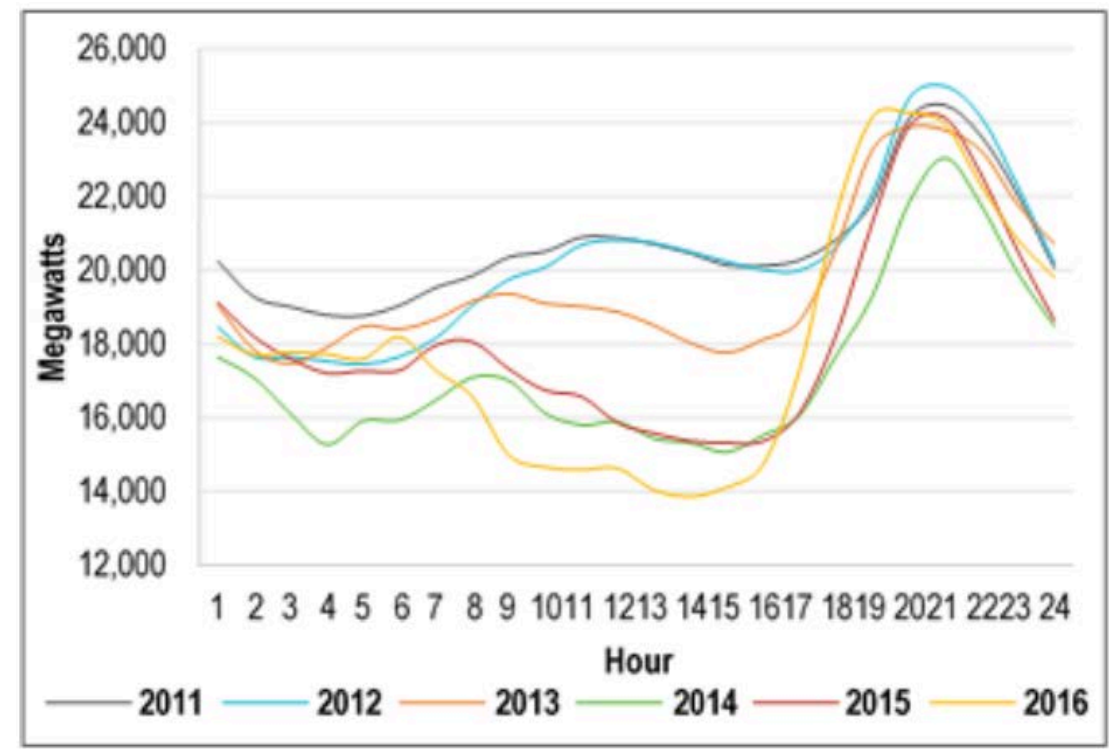

Figure 1. CAISO lowest March daytime net load-non-renewable generation needs.

IIIustration from ScottMadden Management Consultants

Plug-in electric vehicles (PEVs) are a growing source of electricity consumption that could either exacerbate supply shortages or smooth electricity demand curves. Extensive research has explored how vehicle-grid integration (VGI) can be optimized by controlling PEV charging times or providing vehicle-to-grid (V2G) services, such as storing energy in vehicle batteries and returning it to the grid at peak times (Denholm and Short 2006, Göransson et al. 2010). Additional research has focused on optimal pricing models to incentivize demand response and peak shaving (Fitzgerald et al. 2016). While much of this research has modeled charging impacts, implementation in the real world requires a cost-effective solution that accounts for consumer behavior. To function across different contexts, several types of charging administrators and methods of control are necessary to minimize costs in the VGI context. 


\section{Plug-In Electric Vehicle Interface Control}

Most PEVs offer a user interface and web application that allows the driver to program charging times. For example, the Ford SYNC 3 interface shown in Figure 2 allows users to adjust and track their charging times (Ford 2017).

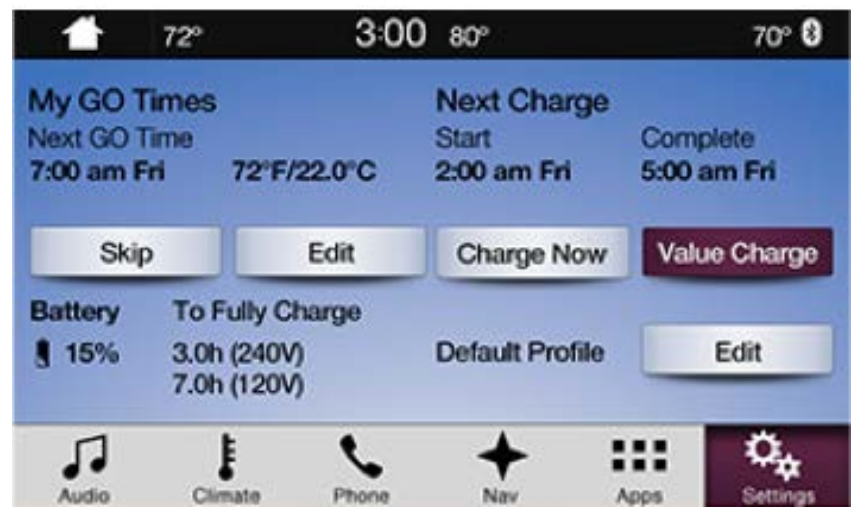

Figure 2. Ford SYNC 3 interface.

\section{Image from Ford Motor Company}

In many cases, this is all the control a PEV owner requires at home to charge at set off-peak times. However, at the aggregate level, the PEV interfaces cannot coordinate charging among different vehicle types and vehicle owners. For example, while PEV interfaces let consumers take advantage of time-of-use (TOU) rates, the consumers acting independently may all set their charging to occur immediately after the off-peak rate goes into effect. Figure 3 shows how consumers in Pacific Gas and Electric territory created a rebound peak in response to TOU rates (ECOtality and Idaho National Laboratory 2013). In regions with low PEV penetration, the rebound peak may not have a significant impact on overall electricity demand, but researchers in the Nordic region have found that $100 \%$ passenger vehicle electrification could increase overall electricity demand by $7.5 \%$, which would yield a significant rebound peak with simple TOU pricing and existing charge control methods (Graabak et al. 2016).

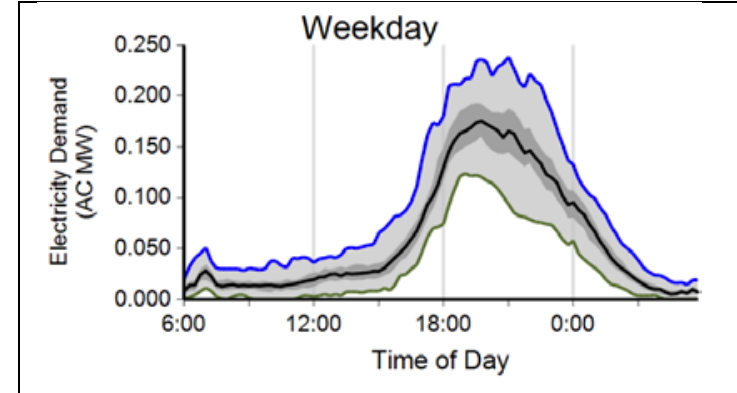

Weekday residential charging demand in NES territory without TOU pricing, Q1 2013

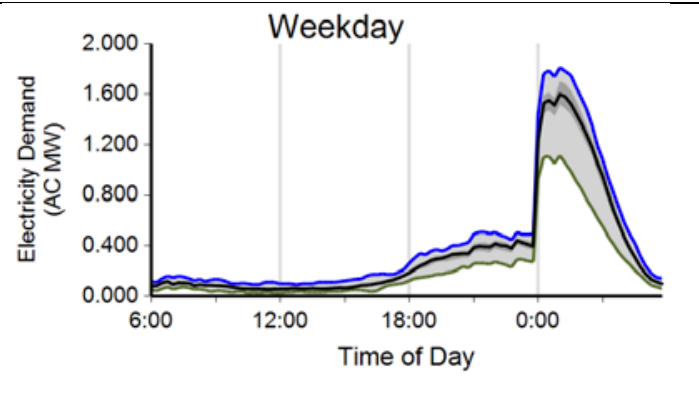

Weekday residential charging demand in PG\&E territory with TOU pricing, Q1 2013

Figure 3. Residential charging demand.

Images from ECOtality and Idaho National Laboratory 


\section{Electric Vehicle Supply Equipment Networks}

Fleets, employers, and others often use electric vehicle supply equipment (EVSE) networks to control charging times, track electricity consumption, or bill employees for EVSE use. EVSE network administrators can dictate charging times for all EVSE units within their control, including times when no PEVs on their network can charge. They can also control EVSE on an individual basis. This takes control away from the drivers, which may be especially problematic for all-battery electric vehicles (BEVs) that may not reach the desired charge before their next trip and do not have a backup power source. An alternative is to require that drivers communicate to the administrator, or charge controller, when the vehicles must be charged.

To control costs or simplify operations, administrators may prefer to use a centralized master controller, such as the HYDRA system diagrammed in Figure 4 (Outwater and Williams 2015). Such systems may also be able to limit PEVs' overall electricity draw and apportion charging rates among the EVSEs. This is helpful in reducing the total capacity requirements of a dense installation of EVSEs to limit exposure to demand charges.

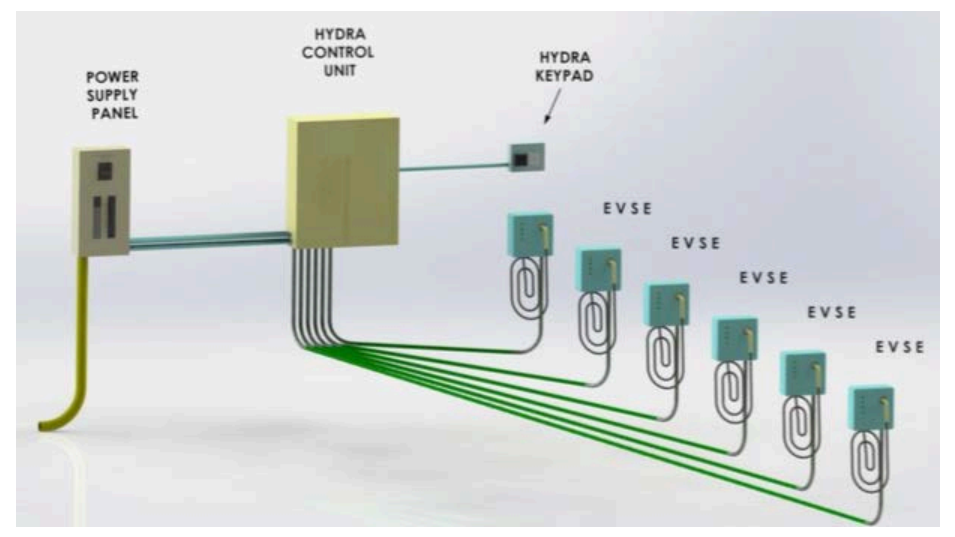

Figure 4. HYDRA EVSE control system diagram.

\section{Illustration from Liberty PlugIns}

EVSE networks can regulate PEV charging loads to reduce EVSE demand at set times, but existing stand-alone EVSE networks are not integrated with facility electricity load. Therefore, their charging schedules may not adjust to unexpected building energy loads, such as cooling on a particularly hot day.

Similarly, EVSE power demand must be integrated with local utility demand to avoid system peaks. Utilities can directly control PEV charging through EVSE networks, for example, by providing a discounted electricity rate in exchange for an agreement to curtail EVSE electricity as needed. This could function like the Xcel Energy air-conditioning "Saver Switch" program, which compensates consumers for allowing the utility to cycle off air conditioners during periods of peak summer demand (Xcel Energy 2017). However, users may choose to override the saver switch, especially if they have urgent transportation needs or range anxiety. At the same time, vehicles are parked and unused most of the time, so there are large periods of time when they could potentially charge. 


\section{Integrated Facility Energy Management System}

Energy management software and hardware can integrate EVSE loads, building loads, and distributed storage or generation such as rooftop solar photovoltaic. This can be used in conjunction with EVSE controls, such as the employee charging management system at the National Renewable Energy Laboratory (NREL), which asks employees to submit their anticipated departure time and charging requirements, and then optimally adjusts charging. Avoiding peaks in the overall demand may help reduce electricity demand charges, which NREL estimates account for over $50 \%$ of their annual workplace charging electricity costs (Jun and Meintz 2017). However, to avoid leaving BEVs out of service when needed, energy managers must work with fleets and employees to ensure that the charging need of vehicles is known by the system so that the vehicles are adequately charged.

\section{Price Signals}

Utilities can influence charging behavior using price signals to encourage consumers to charge at off-peak hours. Simulated models have shown that basic TOU rates can help utilities move PEV charging to off-peak times (Cao et al. 2012), and they can significantly reduce consumer costs to charge (Zhang and Markel 2016). To avoid peak rates, drivers can delay their charging to offpeak times rather than charging as soon as they plug into EVSE. However, TOU rates may result in the rebound peaks shown in Figure 3.

To address rebound peaks and better smooth electricity demand, utilities can employ dynamic electricity rates, which adjust more frequently and with greater precision (Muratori and Rizzoni 2015). These rates require dynamic responses from active or automated energy management (Jin and Meintz 2015). This may be difficult for residential consumers or fleet managers, at least currently, but greater energy automation, third-party aggregation, and consumer buy-in could make this the ideal means of charging control, especially combined with the ability to provide V2G services.

Utilities can also impose a peak demand charge on customers for the 15-minute period in the month when the customer uses the most electricity. Typically in the United States, utilities only apply this rate for commercial and industrial customers, who traditionally have more erratic demand patterns and are better able to control energy consumption through system controls. However, with smart meters, demand response technologies, and PEVs proliferating, consumers may be in a better position to control their peak demand, whether through their PEV interface, EVSE network, facility energy management system, or automated system control. 


\section{Summary and Conclusions}

Table 1 illustrates how all levels of control are appropriate for different users and carry different benefits and drawbacks.

Table 1. Summary of Charging Control Mechanisms

\begin{tabular}{|c|c|c|c|c|}
\hline & PEV Interface & EVSE Network & $\begin{array}{l}\text { Facility Energy } \\
\text { Management }\end{array}$ & Price Signals \\
\hline Administrator & $\begin{array}{l}\text { Consumer, fleet } \\
\text { manager }\end{array}$ & $\begin{array}{l}\text { Consumer, fleet } \\
\text { manager, facility } \\
\text { manager, utility }\end{array}$ & Facility manager & $\begin{array}{l}\text { Utility, facility } \\
\text { manager }\end{array}$ \\
\hline Application & $\begin{array}{l}\text { Control individual } \\
\text { vehicle }\end{array}$ & $\begin{array}{l}\text { Control individual or } \\
\text { multiple vehicles }\end{array}$ & $\begin{array}{l}\text { Control building } \\
\text { and vehicles }\end{array}$ & $\begin{array}{l}\text { Influencing charging } \\
\text { using electricity price }\end{array}$ \\
\hline Benefits & No cost, simple & $\begin{array}{l}\text { Programmable for } \\
\text { multiple vehicles, } \\
\text { simple, flexible }\end{array}$ & $\begin{array}{l}\text { Improved facility } \\
\text { load control }\end{array}$ & $\begin{array}{l}\text { Aggregated at utility } \\
\text { level, relies on } \\
\text { downstream controls }\end{array}$ \\
\hline Drawbacks & $\begin{array}{l}\text { Does not offer } \\
\text { aggregation }\end{array}$ & $\begin{array}{l}\text { No facility } \\
\text { integration, not } \\
\text { standardized across } \\
\text { brands, added cost }\end{array}$ & $\begin{array}{l}\text { Distance of control } \\
\text { from users, } \\
\text { administrative costs }\end{array}$ & $\begin{array}{l}\text { Potential rebound } \\
\text { peaks or complex } \\
\text { price signals and } \\
\text { automated controls, } \\
\text { communication }\end{array}$ \\
\hline
\end{tabular}

All of these technologies only function properly if utilities structure rates to have an influence on charging patterns. At low rates of PEV penetration, simple residential TOU rates can encourage drivers to use the vehicle interface to set charging start times. At high PEV penetration levels, dynamic rates and automated control will better smooth charging loads. Similarly, simple demand rates at commercial enterprises are sufficient in most markets to discourage charging coincident with peak demand. However, integration with facility energy management may better align charging times than a stand-alone EVSE network. 


\section{References}

California ISO. 2016. "What the duck curve tells us about managing a green grid," California Independent System Operator, 2016. Accessed April 5, 2017. https://www.caiso.com/Documents/FlexibleResourcesHelpRenewables_FastFacts.pdf.

Yijia Cao et al. 2012. "An optimized EV charging model considering TOU price and SOC curve," IEEE Transactions on Smart Grid, 3; 1 (March 2012): 388-393. Accessed April 5, 2017. DOI: 10.1109/TSG.2011.2159630.

P. Denholm and W. Short. 2006. An Evaluation of Utility System Impacts and Benefits of Optimally Dispatched Plug-In Hybrid Electric Vehicles. NREL/TP-620-40293. National Renewable Energy Laboratory, Golden, Colorado. Revised October 2006. Accessed April 5, 2017. http://www.nrel.gov/docs/fy07osti/40293.pdf.

ECOtality and Idaho National Laboratory. 2013. "How do PEV owners respond to time-of-use rates while charging EV Project vehicles?" Electric Transportation Engineering Corporation and Idaho National Laboratory, July 2013. Accessed March 1, 2017. https://avt.inl.gov/sites/default/files/pdf/EVProj/125348-714937.pev-driver.pdf.

Garrett Fitzgerald, Chris Nelder, and James Newcomb. 2016. Electric Vehicles as Distributed Energy Resources. Electricity Innovation Lab, Rocky Mountain Institute, Boulder, Colorado. June 2016. Accessed April 5, 2017. http://www.rmi.org/Content/Files/RMI_Electric_Vehicles_as_DERs_Final_V2.pdf.

Ford Motor Company. 2017. "SYNC electric vehicle information screen overview." Accessed April 5, 2017. https://owner.ford.com/how-tos/sync-technology/sync-3/settings/sync-electricvehicle-information-screen-overview.html.

Lisa Göransson, Sten Karlsson, and Filip Johnsson. 2010. "Integration of plug-in hybrid electric vehicles in a regional wind-thermal power system," Energy Policy, 38; 10 (October 2010): 5482-5492. Accessed April 5, 2017. http://doi.org/10.1016/j.enpol.2010.04.001.

Ingeborg Graabak et al. 2016. "Optimal planning of the Nordic transmission system with 100\% electric vehicle penetration of passenger cars by 2050," Energy, 107 (July 15, 2016): 648-660. Accessed April 5, 2017. http://doi.org/10.1016/j.energy.2016.04.060.

Xin Jin and Andrew Meintz. 2015. "Challenges and Opportunities for Transactive Control of Electric Vehicle Supply Equipment: A Reference Guide,” July 2015. NREL/TP-5500-64007. Accessed May 30, 2017. http://www.nrel.gov/docs/fy15osti/64007.pdf.

Myungsoo Jun and Andrew Meintz. 2017. "NREL Parking Garage: EVSE Management," Presentation from the National Renewable Energy Laboratory, February 22, 2017. 
Chris Vlahoplus, Greg Litra, Paul Quinlan, and Chris Becker. 2016. Revisiting the California Duck Curve: An Exploration of Its Existence, Impact, and Migration Potential. ScottMadden Management Consultants. October 2016. Accessed May 30, 2017. http://www.scottmadden.com/wp-content/uploads/2016/10/Revisiting-the-DuckCurve Article.pdf.

Matteo Muratori and Giorgio Rizzoni. 2015. "Residential Demand Response: Dynamic Energy Management and Time-Varying Electricity Pricing," IEEE Transactions on Power Systems, 31; 2 (April 2015): 1-10. Accessed April 5, 2017. DOI: 10.1109/TPWRS.2015.2414880.

Chris Outwater and Forest Williams. 2015. "HYDRA-R: Access Control, Data and Energy Management for Workplace, Fleet and MuD EVSE Systems," Overview presentation from Liberty PlugIns, October 12, 2015. Accessed April 5,

2017. https://www.slideshare.net/ForestWilliams1/hydra-r-overview-cc-151012-56179478.

Xcel Energy. 2017. “Saver's Switch.” Accessed April 6, 2017. https://www.xcelenergy.com/programs_and_rebates/residential_programs_and_rebates/ho $\underline{\text { me energy_efficiency/savers_switch. }}$

Jiucai Zhang and Tony Markel. 2016. "Charge Management Optimization for Future TOU Rates," Preprint. Presented at EVS29: Electric Vehicle Symposium and Exhibition, Montreal, Quebec, June 19-22, 2016. http://www.nrel.gov/docs/fy16osti/66121.pdf. 